\title{
A Study on the Relationship between Feng Shui Interest and Management Performance
}

\author{
Yeon-Su Park \\ Dept. of Financial Accounting, Real Estate Dong-Eui University, Busan, South Korea \\ pghlee@naver.com
}

\begin{abstract}
The purpose of this study is to derive the main factors of Feng Shui site recognition and the effect of the factors on the Management Performance of small business through the previous studies in order to investigate the relationship between Feng Shui interest and management performance for the sake of development of small businesses. In addition, the research is directed to the mediating effect of Feng Shui site recognition and adjusted mediating effect of entrepreneurship in the relationship between Feng Shui interest and management performance. Philosophy, management philosophy, ethics, personality, values, religion. The tendency of success or failure depends on the entrepreneurial world view and life view, such as the living environment. In particular, the location selection and spatial composition of workplaces tend to be determined by the personal factors of the founders. The formation of these personal factors can be said to be the result of accumulated customs of traditional customs or customs closely related to life. However, in many studies so far, especially in the study of commercial area analysis, the search for the relationship between Feng Shui factors and small business management performance, which is deeply embedded in our daily space selection behavior, has been a void of absence. It is necessary not to confine the subject of research to small businesses, but to extend it to medium- or large-sized companies. In addition, it is necessary to research the impact of Feng Shui site recognition not only on the management field but also on other fields.
\end{abstract}

Keywords: Feng Shui interest, Feng Shui site recognition, Management performance, Innovation, Controlled mediating effect

\section{Introduction}

Efforts for the development of small business have been mentioned as important issues in both government and academia. Many studies related to small business have merely focused on factors for management performance or regional roles for development, and whether a number of factors have an effect on management performance. However, none of the studies mentioned how the elements of Feng Shui site recognition, which are closely related to our lives, have an effect on the management performance of small businesses.

In the case of small business start-ups, the success or failure of a company tends to depend on the founder's thoughts and judgments; philosophy, management idea, ethics, personality, values, religion, and living environment. Especially in most cases, the company decides its

Article history:

Received (April 12, 2020), Review Result (May 18, 2020), Accepted (June 21, 2020) 
location and organizes the space according to traditional customs and customs that are closely related to life.

In this regard, this study derives the main factors of Feng Shui site recognition and the effect of the factors on the business performance of small business for the development of small business, and examines through empirical study what kind of controlling function does the entrepreneurship execute and what kind of role does it play in the relationship between Feng Shui space placement and management performance. The purpose of the study is to present basic date that are necessary to promote small businesses.

\section{Theoretical background}

\subsection{Feng Shui interest}

Feng Shui Geography is an Oriental geography and an empirical scientific study, which seek a place for men, animals and plants [Human] to live more healthily and comfortably in the nature by studying the circulation principle of wind and water[Sky], the process of land formation, and the geological conditions based on the Yin-Yang and Five Elements Theory [1].

Feng Shui is basically looking for a way for humans to live together with the nature without getting harm by discriminating between good and bad lands through observing basically the natural phenomena, that is, the movement of wind and water [2]. The purpose of Feng Shui is to enhance the adaptability of human beings to the residential environment by interpreting and discriminating the change of the earth according to the five elements and Feng Shui theory under the assumption that everything in the universe is constantly changing [3]. On the other hand, another purpose of Feng Shui is to set the ancestor's grave at the place with the lively and vigorous energy of earth so that the soul can rest in peace and invoke happy life for the offspring. Therefore, Feng Shui interest can be said to be the degree of application of attitudes and recognition to achieve the purpose of Feng Shui described above.

\subsection{Feng Shui site recognition}

As for space placement, the condition of front-low-rear-high and the principle of entrancenarrow-inside-large means that the gate and entrance located in front of the building should be narrow and the yard or the interior should be wide [4]. As for the space shape, the mutual harmony and synthesis between two energies flowing in the three-dimensional space and the planar space should be formed in the inseparable synchronous relationship, and the ratio of the three-dimensional space and the planar space should be under the condition of $0.577 \sim 0.866: 1$ or $1: 0.577 \sim 0.866$ [5].

In case of junction space, the exterior of the building in junction should be a square and upright with no irregularities to be auspicious. When building a structure on the ground adjacent to the road, there are methods of front, middle and rear layouts depends on how far it is from the road [6]. The purpose of topography is the same as the grave Feng Shui that looks for sites where vitality remains, since house site or residential Feng Shui aim at looking for Jinhyeol where there is full of vitality that flows along a certain path in the ground. However, the difference between the grave and the house is on the size, so when discussing the topographical Feng Shui, the logical structure of Yong, Hyeol, Sa, and Su should be applied [7].

\subsection{Feng Shui analysis of commercial area}


Myeong-dang is the place where the good spirit gathers in traditional Feng Shui. Myeongdang is in a word, a land with a lot of good energy. A good energy is a spirit that gives health to people, makes them feel comfortable, and motivates them to live. A land with especially a lot of good energy was called Hyeol [8]. The size of Hyeol that occupies the most important place in Myeong-dang is generally within a radius of 1 to 2 meters, and about 10 meters at most, so it is very important to find the correct Hyeol in the case of grave. However, in corporate Feng Shui, we must approach the concept of a larger area than the Myeong-dang and Hyeol that fall into the small area where the energy gathers.

\subsection{Management performance}

Management performance is defined in various ways including the ability to achieve organization's goal and acquire the resources needed by the organization, the ability to adapt to changing environments to survive, the ability to develop the human resources and organize to meet the needs of members, and corporate productivity or profitability [9].

\subsection{Innovation}

Miller (1983) argued for three dimensions of entrepreneurship: innovation, progressiveness and risk-taking [10]. Stevenson \& Jallio also categorized into innovative risk-taking to create new value and activities to redistribute or recombine resources progressively [11]. And afterward more various opinions were proposed based on it. Dean et. al. expanded the factors of Miller and added the concept of competitive and aggressiveness [12], and Lumpkin \& Dess also argued that competitive positiveness, independence and autonomy were important components of entrepreneurship [13].

\section{Research design}

In order to empirically verify the flow of research, this study established the following research model to achieve the purpose of research based on the models related to Feng Shui interest, Feng Shui site recognition, management performance, and entrepreneurship suggested in previous studies

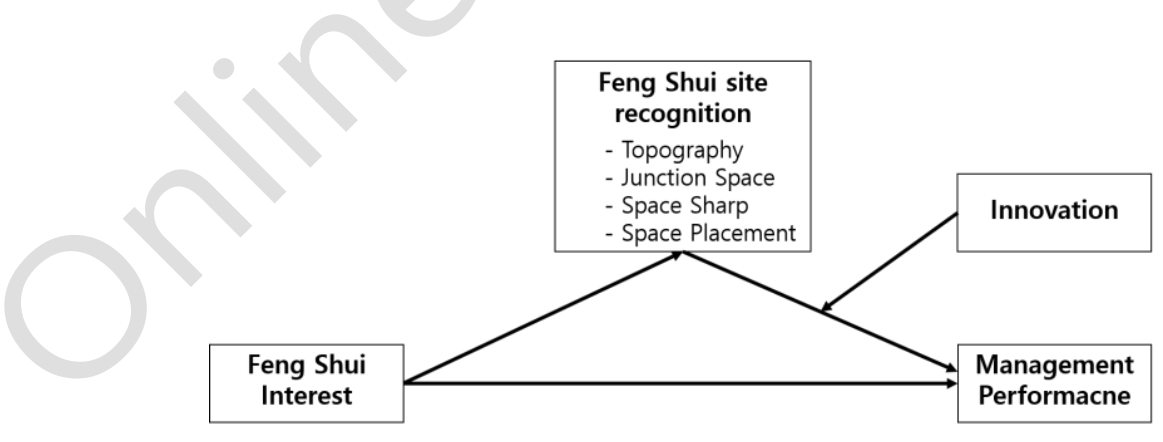

Figure 1. Research model

In addition, the causal hypothesis method was used to grasp the interaction relationship between Feng Shui interest as an independent variable and management performance as a dependent variable, and four hypotheses were set as follows to verify the research model.

$<$ Hypothesis 1> Feng Shui Interest will have a positive effect on Feng Shui site recognition. 
<Hypothesis 2> Feng Shui site recognition will have a positive effect on management performance.

$<$ Hypothesis 3> Feng Shui site recognition will mediate the effect of Feng Shui interest on management performance.

$<$ Hypothesis 4> Innovation will control the mediating effect of Feng Shui site recognition in the path that Feng Shui interest affects management performance through Feng Shui site recognition.

\section{Empirical analysis}

\subsection{Relationship between Feng Shui interest and Feng Shui site recognition}

The results of hypothesis 1, 'Feng Shui interest will have a positive effect on Feng Shui site recognition', are shown in [Table 1]. Feng Shui interest had a significant effect on all the Feng Shui site factors, as the regression coefficient of space placement is $B=.643(t=8.434$, $\mathrm{p}=.00)$, that of space shape is $\mathrm{B}=.6142(\mathrm{t}=7.1978, \mathrm{p}=.00)$, and that of junction space is $\mathrm{B}=.4765(\mathrm{t}=6.2791, \mathrm{p}=.00)$, and that of topography is $\mathrm{B}=.5084(\mathrm{t}=8.2217, \mathrm{p}=.000)$.

Table 1. Regression analysis of Feng Shui interests and Feng Shui site recognition

\begin{tabular}{|c|c|c|c|c|c|c|c|}
\hline $\begin{array}{l}\text { Preceding } \\
\text { Variables }\end{array}$ & Result Variables & Coeff. & SE & $\mathrm{t}$ & $\mathrm{p}$ & $\mathrm{R} 2$ & $\mathrm{~F}$ \\
\hline \multirow{8}{*}{$\begin{array}{l}\text { Feng Shui } \\
\text { Interest }\end{array}$} & Constant & 1.0909 & .2908 & 3.7515 & .0002 & \multirow{2}{*}{.2724} & \multirow{2}{*}{$71.1226 * * *$} \\
\hline & Space Placement & .6433 & .0763 & 8.4334 & .0000 & & \\
\hline & Constant & 1.5141 & .3253 & 4.6543 & .0000 & \multirow{2}{*}{.2143} & \multirow{2}{*}{$51.8080^{* * *}$} \\
\hline & Space Shape & .6142 & .0853 & 7.1978 & .0000 & & \\
\hline & Constant & 1.7963 & .2893 & 6.2089 & .0000 & \multirow{2}{*}{.1719} & \multirow{2}{*}{$39.4271 * * *$} \\
\hline & Junction Space & .4765 & .0759 & 6.2791 & .0000 & & \\
\hline & Constant & 1.8763 & .2358 & 7.9588 & .0000 & \multirow{2}{*}{.2624} & \multirow{2}{*}{$67.5969 * * *$} \\
\hline & Topography & .5084 & .0618 & 8.2217 & .0000 & & \\
\hline
\end{tabular}

\subsection{Relationship between Feng Shui site recognition and management performance}

The results of hypothesis 1, 'Feng Shui site recognition will have a positive effect on management performance', are shown in [Table 2]. Space placement $(B=.1726, t=2.764$, $\mathrm{p}=.063)$, junction space $(\mathrm{B}=.2072, \mathrm{t}=3.4982, \mathrm{p}=.006)$ and topography $(\mathrm{B}=.4379, \mathrm{t}=6.1319$, $\mathrm{p}=.00)$ were found out to be significant, while space shape $(\mathrm{B}=.0593, \mathrm{t}=1.1074, \mathrm{p}=.2696)$ was statistically not significant.

Table 2. Regression analysis of Feng Shui site recognition and management performance

\begin{tabular}{|c|c|c|c|c|c|c|c|}
\hline $\begin{array}{l}\text { Preceding } \\
\text { Variables }\end{array}$ & Result Variables & coeff. & SE & $\mathrm{t}$ & $\mathrm{p}$ & $\mathrm{R} 2$ & $\mathrm{~F}$ \\
\hline Constant & \multirow{3}{*}{$\begin{array}{l}\text { Management } \\
\text { Performance }\end{array}$} & .0888 & .2491 & .3564 & .7219 & \multirow{3}{*}{.5369} & \multirow{3}{*}{$43.1216^{* * *}$} \\
\hline Feng Shui Interest & & .0367 & .0695 & .5274 & .5986 & & \\
\hline Space Placement & & .1726 & .0624 & 2.7644 & .0063 & & \\
\hline
\end{tabular}




\begin{tabular}{|c|c|c|c|c|}
\hline Space Shape & .0593 & .0535 & 1.1074 & .2696 \\
\hline Junction Space & .2072 & .0592 & 3.4982 & .0006 \\
\hline Topography & .4379 & .0714 & 6.1319 & .0000 \\
\hline
\end{tabular}

\subsection{The mediating effect of Feng Shui site recognition in the relationship between Feng} Shui interest and management performance

The bootstrapping method was used to verify the significance of the mediating effect more accurately. In case of verifying the mediating effect using bootstrapping, it can be said that the mediating effect is significant at .05 level unless the $95 \%$ confidence interval for the mediating effect estimate contains zero.

The indirect effect of space placement was significant as $95 \%$ BC bootstrap confidence interval of the results was [0.0272, 0.2083], while the indirect effect of space shape was not significant as $95 \% \mathrm{BC}$ bootstrap confidence interval of the results was [-0.0302, 0.1080].

The indirect effect of junction space was significant as 95\% BC bootstrap confidence interval of the results was $[0.0446,0.1648]$, and the indirect effect of space shape was significant as $95 \%$ BC bootstrap confidence interval of the results was [0.1421, 0.3158].

Therefore, space placement, junction space and topography were found out to have a mediating effect on the relationship between Feng Shui interest and management performance, while space shape does not have.

Table 3. Bootstrap verification for analysis of mediating effects of Feng Shui site recognition

\begin{tabular}{|c|c|c|c|c|c|}
\hline \multicolumn{2}{|c|}{ Variables } & Coeff. & SE or Boot SE & LLCI & ULCI \\
\hline \multirow{2}{*}{ Direct Effect } & & .0367 & .0695 & -.1005 & .1738 \\
\hline \multirow{3}{*}{ Indirect Effect } & Space Placement & .1110 & .0449 & .0272 & .2083 \\
\cline { 2 - 6 } & Space Shape & .0364 & .0353 & -.0302 & .1080 \\
\cline { 2 - 6 } & Junction Space & .0987 & .0305 & .0446 & .1648 \\
\cline { 2 - 6 } & Topography & .2227 & .0438 & .1421 & .3158 \\
\hline
\end{tabular}

\subsection{The adjusted mediation effect of innovation in the relationship between Feng Shui interest, Feng Shui site recognition and management performance}

Table 4. Bootstrap verification of significance of mediating effect controlled by innovation

\begin{tabular}{|c|c|c|c|c|c|}
\hline \multicolumn{2}{|c|}{ Variables } & Coeff. & SE or Boot SE & LLCI & ULCI \\
\hline \multirow{2}{*}{ Direct Effect } & & .0947 & .0723 & -.0480 & .2374 \\
\hline \multirow{3}{*}{ Indirect Effect } & Space Placement & .0334 & .0501 & -.0647 & .1315 \\
\cline { 2 - 6 } & Junction Space & -.0655 & .0341 & -.1326 & .0042 \\
\cline { 2 - 6 } & Topography & .0923 & .0544 & -.0166 & .1964 \\
\hline
\end{tabular}

The analysis of adjusted mediation effect of innovation of entrepreneurship, showed that the higher the innovation of entrepreneurship is, the more the indirect effect of the adjusted mediating effect increases as shown in [Table 3] and [Table 4] $(-1 \mathrm{SD}=.1578$, mean $=.2406$, 
$+1 \mathrm{SD}=.3233$ ). In addition, all three groups of innovation are statistically significant as they do not contain zero between the lowest limit and highest limit value of indirect effect.

\section{Conclusion}

This study derived key factors of Feng Shui site recognition for the development of small business and self-employed business in Busan, Gyeongnam, and Gyeongbuk, and examined the effects of these factors on the management performance of small business owners.

In addition, the research tried to present basic data necessary in promoting small business owners by examining comprehensively through empirical research which adjusting function will the entrepreneurship brings about in the relationship between Feng Shui site recognition and management performance, and the mediating role of Feng Shui site recognition in the relationship between Feng Shui interest and management performance.

The results obtained from the analysis can be summarized as follows.

The weaker the trend of Feng Shui interest, the lower the Feng Shui site recognition (space placement, space shape, junction space and topography). And the lower Feng Shui site recognition means that the lower management performance is predicted. The stronger the trend of Feng Shui interest, the higher the Feng Shui site recognition. And the higher Feng Shui site recognition means that the lower management performance is predicted. In addition, the adjusted mediating effect shows statistically significant, as it is observed that the higher the innovation. The more the management performance is amplified, while the lower the innovation, the more the positive influence of management performance is decreased.

These results imply that the effects, which appear in the path of Feng Shui interest, Feng Shui site recognition (space placement, junction space and topography) and management performance, can be significantly adjusted according to the innovation of entrepreneurshipp.In particular, it suggests that the mediating effect of Feng Shui site recognition in between the Feng Shui interest and management performance can be more greatly experienced when the innovation is high.

Existing previous studies have been conducted mainly through case studies, but this study could provide specific data to small business owners through empirical analysis. The significance of this study is in that it can provide the basis for applying Feng Shui site recognition to small business owners who are preparing or starting a business in the future.

\section{References}

[1] Song Seung-Ho, "A geomantic study on location and space composition of hyang-gyo in ulsan area," M.S. thesis, Yeong-Nam University, Dae-Gu, Korean, pp.8, (2019)

[2] Seo Kyung-Im, "A study on the position of the yeongguk temple of mt. cheontae by the feng-shui," M.S. thesis, Yeong-Nam University, Dae-Gu, Korea, pp.6-7, (2018)

[3] Hong Seong-Seo, "A study on donggigameung in theory of topographic divination: focused on cases of outbreak of disease," Ph.D. dissertation, Yeong-Nam University, Dae-Gu, Korea, pp.9, (2009)

[4] An Hae-Woo, "The research for the effects of the geomantic system of topography used in choosing auspicious sites for houses,” M.S. thesis, Jung-Ang University, Seoul, Korea, pp.46, (2008)

[5] Park. Yeon-Su, "A study of the identity of house shape and house destiny when the feng-shui habitation has an effect on family circumstances," M.S. thesis, Dong-Guk University, Seoul, Korea, pp.43, (2012)

[6] Sim. Jae-Yeal, "A study on the effect of feng shui on the determinant of location selection," Ph.D. dissertation, In-Cheon University, In-Cheon, Korea, pp.106, (2010)

[7] Park Mu-Heoml, "The study of correlations with the principle of topography and anatomy in viewpoint of oriental medicine," Ph.D. dissertation, Young-San University, Busan, Korea, pp.95, (2011) 
[8] Park Si-Ik, "A study on the background and origin of Feng-Shui theory," Korea University, vol.5, pp.184189, (1987)

[9] Jung So-Jin, "A study on the influence of franchisor's support on relation bonding between franchisor and franchise and long-term relationship," M.S. thesis, Dong-A University, Busan, Korea, pp.38, (2006)

[10] Miller D. and Friesen P. H., "The correlates of entrepreneurship in three types of firms," Management science, vol.29, no.7, pp.770-791, (1983)

[11] Stevenson H. H. and Jarillo J. C., "A paradigm of entrepreneurship: entrepreneurial management," Strategic management journal, vol.11, no.5, pp.17-27, (1993)

[12] Stevenson H. H. and Jarillo J. C., "Corporate entrepreneurship and competitive aggressiveness: a comparison of us firms operating in eastern Europe and the commonwealth of independent states with us firms in other high risk environments," Advances in International Comparative Management, vol.8, pp.31-54, (1993)

[13] Lumpkin G. T. and Dess G. G., "Clarifying the entrepreneurial orientation construct and linking it to performance,” Academy of management Review, vol.21, no.1, pp.135-172, (1996) 
This page is empty by intention. 